\title{
Zapadno- i južnoslavenski romantizmi kao epoha demokratizacije kulture
}

AвSTRACт: Zieliński Bogusław, Zapadno- i južnoslavenski romantizmi kao epoha demokratizacije kulture (Romanticism in West and South Slavonic Literature as the Epoch of Democratization of Culture). "Poznańskie Studia Slawistyczne" 17. Poznań 2019. Publishing House of the Poznań Society for the Advancement of the Arts and Sciences, Adam Mickiewicz Univesity, pp. 321-333. ISSN 2084-3011.

If we regard democracy as tied with four functions: availability, representation, freedom, and education, then we can state that the Romanticism conceived as the intellectual formation and literary current has managed to realize the deepest and thorough process of democratization of culture, of which results remain valid and actual in our contemporary reality. In the Romanticism, two traditions converge in order to construct its progressive character: the educational tradition derived from the German idealism and the liberation one. The educational tradition has been inspiring the development of knowledge, education and university values by shaping the holistic conception of education and personal progress. In this article, the educational orientation of the Romanticism is expressed by the function of availability concerning culture as well as education. The liberation current of the Romanticism is related with the French tradition, peoples as a subject that debates on the ideas of justice and injustice, and also with the folklore along with the independence narrative. The titular category namely, democratization of culture should be understood as a multifaceted phenomenon of the gradual and irreversible processes of innovations which have spread through the spheres of culture, language, system of forms of utterance in order to shape various social and cultural institutions, which - throughout the process of generating new literary canons and redefining modern national identities - eventually contributed to the constitution of the contemporary states.

Keywords: Romanticism; Romanticism in West and South Slavonic literature; democratization of culture; modern Slav national identities

Nastanak romantizama nije slučajno povezan s prijelomom, buntom i konfliktom s prethodnom epohom, nego i s negiranjem svjetonazorskih temelja prosvjetiteljstva i klasicizma, novom vizijom svijeta i filozofije povijesti, formiranjem romantičarske antropologije koja pretpostavlja krajnji individualizam, kreiranjem romantičarskog junaka i novom, širom 
estetskom osnovom umjetnosti, književnosti i kulture. U svakom od tih područja romantizam je označavao nobilitaciju i širenje opsega društvene recepcije kulture, identificiranje njezinih narodnih i folklorističkih osnova $-\mathrm{u}$ duhu Herderova učenja vjere $-\mathrm{s}$ trajnom i suštinskom stvarnošću naroda.

Ako s demokracijom ${ }^{1}$ povežemo četiri funkcije - dostupnost, reprezentativnost, slobodu i obrazovanje - možemo konstatirati da je romantizam kao intelektualna formacija i književni pravac ostvario najdublji, najsvestraniji proces demokratizacije kulture čije posljedice traju i danas. U romantizmu se susreću dvije tradicije, stvarajući njegov aktualni i napredni karakter. Obrazovna tradicija, koja potječe od njemačkog idealizma, i slobodarska tradicija, kojoj je najjači impuls dala velika Francuska revolucija (Lyotard, 1997, 92-94). Obrazovna tradicija inspirirala je razvijanje znanja, školstva i sveučilišne tradicije, formirajući holističku koncepciju obrazovanja i razvoj ličnosti. Obrazovni smjer romantizma u ovom tekstu izražavaju funkcije dostupnosti kulture i obrazovanja. Slobodarski smjer romantizma povezan je s francuskom tradicijom, narodom kao subjektom koji diskutira o onom što je pravedno i nepravedno, povezan sa smjerom folklora i naracijom nezavisnosti. Sloboda i reprezentacija su funkcije koje se u ovom tekstu vezuju za francuske inspiracije romantizma. Aktualnost romantizma, s kojim povezujemo suvremeni kod slobode, zatvara stvarnost u spoj emancipacije i subjektiviteta, pri čemu ideja emancipacije označava ukidanje osobnih zavisnosti, a ideja subjektiviteta - suverenitet naroda (Filipowicz, 2018, 3).

\section{Dostupnost}

Pod realizacijom načela dostupnosti podrazumijevam pojave, strategije i procese kreirane u okviru kulture, a koji proširuju krug adresata kulture. Dostupnost je također ostvarena putem različitih institucija,

${ }^{1}$ Iz obimne literature o teoriji demokracije vrijedi navesti nekoliko naslova koji razmatraju različite teorijske struje: Michael Saward, Demokracja, prev. Aleksandra Burek, Warszawa 2008; Charles Tilly, Demokracja, prev. Michał Szczubiałka, Warszawa 2008; William J. Hoye, Demokracja a chrześcijaństwo. Chrześcijańska odpowiedzialność za zasady demokracji, prev. Stanisław Jopek SJ, Kraków 2003. 
čiji je zadatak distribuiranje sadržaja i vrijednosti kulture. Romantizam je radikalno povećao dostupnost književnosti, obavljajući standardizaciju književnih jezika, a romantičarska estetika s folklorističkom paradigmom i nova genološka hijerarhija (balada, romantičarska drama, budnica, davorija) učinile su da je romantizam $u$ dotad neviđenoj mjeri proširio društveni subjekt kulture. U institucionalnom pogledu treba istaknuti razvoj institucija koje, iako su često potjecale iz ranijih razdoblja, ali su se razvile u romantizmu, povećavaju opseg djelovanja i imaju više funkcija. Riječ je prije svega o znanstvenim društvima, mreži narodnih muzeja, javnih čitaonica, izdavanju časopisa i sl.

Standardizacija. Slavisti, a posebno južni slavisti, ističu značenje standardizacije novoštokavštine $u$ formiranju hrvatskog i srpskog suvremenog kulturnog i nacionalnog identiteta. Na daljnjem planu je pitanje šireg konteksta tih procesa, jer su Karadžićeva (Pismenica serbskoga jezika po govoru prostoga naroda napisanu, 1814.) i Gajeva (Kratka osnova horvatsko-slavenskoga pravopisanja, 1830.) reforma bile neobično važne i do danas su značajne za uzajamne srpsko-hrvatske odnose. Standardizacija je ipak bila autonoman, neobično važan proces, koji je započeo u Češkoj pola stoleća ranije u atmosferi novog pokreta građanske demokracije. Józef Dobrovský, ,patrijarh slavistike“, započeo je epohu Bohemia docta (Učena Češka), iako je imao barokne prethodnike na polju filološke djelatnosti (Szyjkowski, 1948, 10-19). Nacionalni preporod se mogao dogoditi, kako su u to vjerovali buditelji, jedino putem preporoda češkog jezika. Lingvistički karakter češkog nacionalnog preporoda proisticao je iz uvjerenja koje potječe od Herdera i Kollára, da je narod jezik, a duh naroda izražava njegov jezik. Jezična orijentacija češkoga nacionalnog preporoda izražava se i u činjenici da je samo u razdoblju 1775. - 1825. objavljeno 28 čeških obrana jezika (mluvnica), 28 jezičnih traktata i 14 izdanja rječnika. Fenomen preporoda počeo je od „obrana češkog jezika“, jer je najvažnija paradigma češkog nacionalnog preporoda bio lingvistički aspekt. Paradoksalno je da su taj pokret započeli njemački pisci: Gelasius Dobner (1719. - 1790.), osnivač škole historijskog kriticizma i njegov učenik Adaukt Voigt (1733. - 1784.). Drugu generaciju čeških i slovačkih buditelja činili su istraživači koje je Mickiewicz nešto kasnije nazvao „,̌eškim filolozima“: Josef Jungmann (1773. - 1847.), Wacław Hanka (1791. - 1861.), Jan Kollár (1793. - 1852.), Pavel Jozef Šafařik (1795. - 1861.) 
i F. L. Čelakovsky (1799. - 1852.) (Szyjkowski, 1947, 5-6). U području povijesti tu djelatnost je nastavio František Palacký (1798. - 1876.) (Orłoś, 2000, passim). Češki aktivisti preporoda, jezični inženjeri, svoju su lingvističku djelatnost vidjeli kao pomoć u ozdravljenju, jer su jezik tretirali kao odliku zdravstvenog stanja pacijenta, a budući da je narod bolestan, pacijentu je potrebna brza i radikalna pomoć. Medicinsku demokraciju pratila je vojnička demokracija. Jungmann je bio uvjeren da književnost mora biti ne samo zdrava nego prije svega slobodna. Husitsku koncepciju obrambenog tabora preuzeo je nacionalni preporod. Književnost je metaforički vojni tabor, u kojem se narod bori i gradi rovove svoje obrane. Pisac mora biti više vojnik nego umjetnik (Macura, 1995, 122).

Djelatnost čeških buditelja kretala se putem razdvajanja svojih i tuđih, spašavanja češkog jezika od dominacije njemačkog jezika. Hrvatski i srpski reformatori išli su putem slovačkih djelatnika, koji su pokretali jezične reforme u uvjetima niskog praga razlika između češkog i slovačkog jezika. Reformi Ljudevita Štura (obožavatelja Kollára i predvodnika generacije [tzv. šturovaca] čiji je cilj bilo konstituiranje slovačkog naroda, kodifikacija slovačkog književnog jezika i izdvajanje slovačke nacionalne i povijesne tradicije kao osobina nacionalnog identiteta po kojima se razlikuju) prethodila je djelatnost prosvetiteljskih filologa, Bernolaka (1762. - 1813.) i Palkoviča (1769. - 1850.), koji su podržavali tradiciju češko-slovačke unije (Goszczyńska, 2008). Šturovci su put k nezavisnosti i konstituiranju naroda vidjeli u narodnom jeziku, koji će bolje nego bibliština obavljati državotvornu funkciju. Gotovo mesijanistički kult slovačkog jezika iskazuje veza između slavenofilskih pogleda na jezik, kulturu i narod te građanske demokracije koja se formira na ruševinama staleškog društva (Janaszek-Ivaničková, 1978, passim). Romantičari su bili svjedoci rađanja kapitalizma, a često i žrtve birokratsko-policijske kontrole pojedinaca i čitavih zajednica od strane represivnih aparata militarističkih država (Chlebowczyk, 1979, 9-10).

\section{Reprezentativnost}

Romantizam-umjetnost-stvarnost. Romantizam je negirao prosvjetiteljsku vjeru u harmoničan sustav odnosa između pojedinca i društva, izražavao je uvjerenje da je među njima neizbježan konflikt, prihvaćao je 
pobunu protiv svijeta i okoštalih društvenih odnosa. Buntovnički stav bio je jedan od glavnih duhovnih elemenata romantičarskog junaka. U prvom planu istaknut je osjetljivi pojedinac, često s osobinama natprosječnosti, koji je vodio usamljeničku borbu s tradicionalnim načinima mišljenja i društvenim poretkom uime interesa kolektiva (bajronizam, prometeizam, valenrodizam) ili je preuzimao ulogu izražavatelja uvjerenja ili duhovnog predvodnika čitave zajednice.

Romantizam je umjetnost smatrao savršenom formom spoznaje, koja može dati simbolički ekvivalent skrivene suštine bitka. Romantičari su književnost tretirali kao formu individualne ekspresije, koja uvodi originalne inovacije u zatečen sustav tradicije. Priznavali su joj istovremeno ulogu izražavatelja istina i težnji nacionalnog kolektiva, a pjesniku ulogu duhovnog vođe i nacionalnog proroka (profetizam). U poljskoj književnosti to je pronašlo izraz u koncepciji wieszcza (barda, proroka).

Apoteoza nacionalne ideje koju je izražavao pisac-prorok, bard (wieszcz) dovela je do toga da je romantizam postao stroj za stvaranje novih kulturnih i nacionalnih identiteta (Dziady, Oda do młodości, Pan Tadeusz, Hrvatska domovina, sveslavenska himna). Romantizam je ustanovio kanon književne tradicije koji obvezuje buduće stvaratelje i predstavlja opći komunikacijski kod u kojem su se zbivali tadašnji sporovi. Demokratski karakter romantičarske svjetonazorske i estetske revolucije - jer je romantizam bio efikasan proces opće društvene emancipacije - zatiru utopijske slavenofilske i ilirske ideje. Kollárove Córy Stawy (Kćeri Slave) u prvom su planu manifest sveslavenstva. To je ,pjesnički program nacionalnog preporoda“, „evanđelje slavenstva u preporodu“ - takvim je epitetima Vraz opisivao Kollarovu poemu u pismu Gaju iz 1834. godine. Tek dubljom refleksijom dolazi se do zaključka da Kollárovo slavenofilstvo stvara nove vrste društvenih veza, novi tip patriotizma i nacionalne kulture, proniknute suvremenim, modernističkim duhom. Demokratske ideje slavenofilstva povezane su s utopijskom slikom Slavena, kao naprimjer miroljubivost, marljivost, hrabrost i heroizam u obrani slobode, ali nisu u suprotnosti s vrijednostima demokracije. Slaveni su prije svega pobožni seljaci, vrijedni, pravedni, plemenita karaktera, ali i puni hrabrosti i dostojanstva. Idealiziranje slavenskog karaktera, vjera u budućnost čitavog plemena i ideja jedinstva Slavena te kult pjesme postaju ,produžetak narodnosti u prošlost“" plemenske demokracije (Štefánek, 1937, 341). 
Folklor. Romantizam je posebno značenje pridavao narodnom i primitivnom stvaralaštvu koje je ostvarivalo ideal iskrenosti osjećaja, prirodnosti i jednostavnosti kao najviših vrijednosti života i umjetnosti. Ostvarujući ideje demokratizma, romantizam je nobilizirao razne uzore perifernih i provincijalnih kultura, suprotstavljanih neautentičnoj zvaničnoj kulturi. Odbacujući normativizam i negirajući vrijednosti stalnih uzora, romantizam je preoblikovao glavne književne žanrove i stvorio sebi svojstvene vrste književnog iskaza.

Balada je u slovačkoj književnosti omogućavala razvoj nacionalne književnosti utemeljene na nacionalnoj povijesti, kao i njezino zasićivanje narodnim i slavenskim elementima. Dvadesetih i tridesetih godina logika šturovskog pokreta davala je prednost tematici iz nacionalne povijesti, eksponirajući veličinu i sjaj nacionalne povijesti, čiji je prirodni prijenosnik bila, naravno, balada, koja je pridonijela učvršćivanju građanske svijesti novog tipa. Ballady i romanse (1822.) Adama Mickiewicza postale su u ranom romantizmu žanr koji služi polemici s prosvjetiteljskom vizijom svijeta, ali - izvan narodnog karaktera - duboka ukorijenjenost u povijesnim i lokalnim realijama eksponira ulogu moralne paradigme, jer ono što je natprirodno ocjenjuje ljudska djela i uvodi moralni red, nameće odgovornost za djela te izriče kaznu za počinjeno nedjelo (Magnuszewski, 1956, 100-123).

\section{Sloboda}

Romantizam je napokon nudio slobodu, najvažniju kategoriju demokratskog svijeta. Sloboda romantičara stimulirala je romantičnu slobodu, jer je vrhovni atribut romantičara - genije, osećaj i mašta, dajući uvid u skrivene smislove bitka, u književnim reprezentacijama, predstavljao manifest individualne, društvene i nacionalne slobode (himnografija).

Postulat romantične slobode bio je uvučen u kontekste i paradokse modernizacijskog preokreta, jer s jedne je strane romantizam bio pokretač modernizacije, redistribuirajući optimizam, nadu i nudeći realizaciju velikih projekata Popravljanja svijeta, a također najavljuje avangardizam, prometeizam (Kuziak, 2009, 9). Međutim, s druge strane, romantizam je u slavenskim zemljama istovremeno bio radikalna kritika modernizacije 
i apologija tradicije. Zahvaljujući inspiraciji Rousseauom, mogao je označavati glorifikaciju prirodnog stanja. Tim tragom su išle hrvatske himne Mihanovića i Gaja, nudeći ideale idilične ili utopijske zajednice.

Himnografija. Slavenska himnografija je vjerojatno najizrazitiji primjer romantičarske modernizacijske ideje koja formira suvremeni humanistički i demokratski patriotizam (Brtáň, 1972, 58). Uzor za široki opseg romantičarske slavenske himnografije bila je Mazurka Dąbrowskog (1797.) i eshatologija naroda i države koja izrasta iz poljskog romantizma, a predstavlja uzor zajednice koju spaja misterij smrti i uskrsnuća. „Ono što je umiralo, ono što je bilo blizu smrti i gotovo umrlo, može se preporoditi bolje. Iskustvo groba, blizine smrti, oduzimanja države, razdvajanja na obamrlo i živo istovremeno je približavanje univerzalnom izvoru života“ (Maleszyński, 2002, 193). Golemu popularnost stekla je Mazurka Dąbrowskog u zemljama zapadnog, južnog i istočnog slavenskog svijeta. O tome svjedoče njezine brojne adaptacije. Pjesma Još Poljska nije propala 35 godina nakon nastanka inspirirala je poslije 1831. godine Slovake koji su je zapisivali i parafrazirali (Gołąbek, 1924, 139). Samo Tomšík je 1834. godine na njezinu melodiju napisao besmrtnu sveslavensku himnu, pjesmu Hej rodáci - Hej Slováci (Krčmery, 1927, 3-4). Hrvatske himne, Gajeva Još H(o)rvatska nij(e) propala / dok mi živimo (1833.) i Mihanovićeva Lijepa naša, kao i češka himna iz singspiela Fidlovačka aneb Žádný hněv a žádná rvačka (1834.), nastale su u istom razdoblju, a povezuje ih prisutnost jakog sentimentalno-arkadijskog elementa, što ne umanjuje moderni karakter patriotske i građanske ideje. Pjesma iz Fidlovačke seže po staru tradiciju arkadijskog viđenja češke zemlje iz opisa Kosmasa, a vezana je za stvaralaštvo Hieronima Balbusa, koji je o Češkoj pisao kao o „Arkadiji, zemlji lijepoj“ i koristio ideologem Paradisus Bohemia (Plavec, 1941, passim).

Himne inspirirane Mazurkom Dąbrowskog poprimile su formu specifičnih, različitih stilističko-žanrovskih uzora, uvjetovanih prije svega onime kako je izgledala nacionalna tradicija. Hrvatske himne su primjeri specifične poetike ilirizma u kojima se pojavila izrazita suprotnost između klasične i sentimentalne stilističko-žanrovske forme, romantičarskog društvenog programa i političke utopije obnove ilirskog naroda. Hrvatske himne se nadovezuju na tradiciju patriotske prosvjetiteljske lirike s izrazitim narodnim elementima, ostvarujući sentimentalni i pastoralno-arkadijski 
model. Hrvatska himna Lj. Gaja model je sentimentalnog djela tipa „glas osjećajnog srca“, a himna A. Mihanovića tipa „glas netaknute prirode“. Gajeva himna znači okretanje ka svijetu, pronicljivu opservaciju situacije drugih ljudi i emocionalnu reakciju na nju. Mihanovićeva himna, koja se nadovezuje na tradiciju idile (bogatu u hrvatskoj književnosti), označava okretanje ka ljudskom srcu, slušanje glasa netaknute prirode. Ideja ,glasa netaknute prirode" Mihanovićeve himne potječe iz misli Rousseaua. Što se tiče svjetonazora, Gajeva himna je karakteristična za sentimentalizam, jer su njene glavne osobine emocije, priroda, srce i vrlina. Iz tradicije Lockea i Humea potječe shvaćanje emocija kao prvobitne sposobnosti čovjeka, problem čovjekove prirode. Mihanovićev patriotizam čvrsto povezuje pojam domovine i prirode, spajajući ono što je narodno, duhovno i moralno, formirajući suvremeni humanistički i demokratski patriotizam, jer su njegove diskriminante narod, solidarnost i rad (Zieliński, 2000, 34-49; 2018, 313-322).

Sveslavenska himna koja utjelovljuje ideju „slavenskog duha“ u modelu trajanja i vjernosti prosvjetiteljske provenijencije pod utjecajem poljskog mesijanizma uvodi općeslavenski karakter ideje nacionalnog preporoda, te građanska ideja postaje floskula, a demokratizacija dobiva značenje općehumanističke zajednice.

Sloboda i suvremenost. Mickiewicz u Dušnom danu kritizira suvremenost kao posljedicu prosvjetiteljstva koje dovodi u pitanje duhovnost, a s druge strane kao posljedicu kulture kaosa mnoštva knjiga koji su uzrok izgubljenosti čovjeka. Za Mickiewicza suvremenost je ambivalentna pojava, jer ga je s jedne strane suvremenost formirala (Stefanowska, 1962, 88), a s druge je strane pokušava parafrazirati, pridajući napretku moralna i duhovna značenja (u pariškim predavanjima) koji su napredak na putu ka Bogu (Kuziak, 2009, 97). Tu se pojavljuje pitanje subjektivnog modernizacijskog stava koji je obuhvaćao niz mogućnosti, izražavajući se također u različitim modelima identiteta (nacionalna, ilirska ili panslavistička identifikacija kao identitetske formule). Romantičarska sloboda je definirana i kao koncepcija Ja beskonačno slobodne, spontane, kreativne sile, izvan poretka empirijskog svijeta, kao i dekonstrukcijske koncepcije koje u ideji romantičarske slobode vide tragove suvremenosti odnosno ironije: ideju duše koja osjeća, koja je u svijetu i podliježe utjecajima (Bielik-Robson, 2008, 78-79). 
Romantičarska demokratska paradigma bila je povezana s raspadom tradicionalnih kulturnih okvira, formiranih na temelju sredozemne kulture kojima se završava epoha reda i kojom počinje epoha povijesti i čovjeka (Foucault, 2005, 11, 116). Nove mitologije suzile su okvire egzistencijalnih filozofskih i svjetonazorskih repera, preferirajući nacionalne i moderne mitologije, u skladu s duhom društava koja se moderniziraju i ogledaju u ogledalu nacionalnih narcizama.

Borba romantičara za slobodu bila je upletena u paradokse, kontradiktornosti i iluzije, koje su u neku ruku bile posljedica nedovoljno razvijene teorije naroda, lingvističkog znanja i teorije kulture, čije je negativne posljedice preuzelo XX. stoljeće (ilirska ideja, slavenska ideja, antiokcidentalizam).

Sentimentalno-klasicistički narodni duh Ilira i narodni duh Mickiewicza zasebni su uzori. Narodni duh Ilira trebao je izražavati utopiju prvobitnog slavenstva i idiličnosti, koja je bila odraz Herderove misli, a na njega je još došao Rousseauov model naturalizacije kulture. Hrvatski „,buditelji“ se služe arkadijskim toposom, idealiziraju prirodni karakter međuljudskih veza, definiraju čovjeka psihologistički, introspektivno i senzualistički. Mickiewiczev narodni duh isticao je vezu poezije i naroda, geografskog mjesta $i$ istorijskog vremena, situiran je bio na suprotnim polovima mimetičkih koncepcija. Upisivao se u romantičarsku tradiciju srednjeg vijeka, ali je otkrivao zasebnosti nacionalnog identiteta, utemeljene na različitim folklorima narodâ europskog sjevera (Makowski, 1999, 65).

\section{Obrazovanje}

Pokretač demokratizacije i društvenog obrazovanja u vrijeme romantizma bile su institucije, časopisi, škole i kazališta. Mnoge od tih institucija nastale su najprije u Češkoj. Važnu ulogu u preporodu češkog jezika odigrala je Učená společnost, znanstveno društvo osnovano 1773./1774. godine, kao i Královská česká společnost, osnovana 1784. godine. Druga važna ustanova koja je poticala znanstveni život češke zemlje bio je Narodni muzej, koji je osnovao Kasper Šternberg 1818. godine (Kočí, 1978, passim). Nastaju čuvene kulturne institucije: Matica srpska (1826.), Matica česka (1831.), Matica ilirska (1842.), Narodni zavod Ossoliński (1817.), 
Varšavsko društvo prijatelja znanosti (1800. - 1832.), od 1808. Kraljevsko društvo prijatelja znanosti, Poznanjsko društvo prijatelja znanosti (PTPN), koje postoji od 1857. godine sa sjedištem u Poznanju, a okuplja danas oko tisuću znanstvenika iz cijele Poljske koji čine korporaciju na pravima društva.

U Poljskoj su autoritet Dobrovskog ubrzo prepoznali i potvrdili članovi Društva prijatelja znanosti u Varšavi 1813., kao i članovi krakovskog Društva prijatelja znanosti (na inicijativu Bandtkog). Godine 1818. Dobrovský je nominiran za počasnog člana sveučilišta u Vilniusu. Na inicijativu Palackog 1830. nastaje Institut za češki jezik i književnost (Sbor pro vědecké vzdělání řeči a literatury české), koji je bio temelj godinu kasnije osnovanoj Matici češkoj (Szyjkowski, 1948, 23-38).

Jungmann, rektor Karlova sveučilišta u Pragu, od 1827. godine je član varšavskog Društva prijatelja znanosti, a od 1830. i krakovskog Društva prijatelja znanosti (Szyjkowski, 1948, 40).

Češko kazalište postalo je nositelj preporodnih ideja i društvene patriotske edukacije širokih narodnih krugova. Preporodni djelatnici imali su dobro utemeljenu kazališnu kulturu i nisu gubili iz vida obrazovne i estetske mogućnosti koje kazalište sa sobom nosi. Kazalište je u svim slavenskim zemljama odigralo veliku ulogu u popularizaciji i širenju društvenog adresata kulture, ali je u Češkoj taj pravac nastao najranije i bio je najsnažniji. Iz tog ćemo se razloga ograničiti na svega nekoliko čeških primjera. Tradicije narodnog baroknog kazališta u razdoblju preporoda počele su se razlikovati od repertoara preporodnog građanskog kazališta, koje je rado sezalo za klasičnim umjetnostima. Narodno preporodno kazalište stvorilo je formu tzv. seoskih (susjedskih) umjetnosti, u kojima zabava, faktor spoznaje i folklor čine nedjeljivu cjelinu. Seoske umjetnosti činile su početak profesionalnog kazališta velikih gradova i amaterskoga građanskog kazališta. Inspiracija za umjetničke tekstove bila su djela za narod, stari romani, legende i kronike (Kalista, 1942, 67). One su odvojile kazalište od religioznog baroknog repertoara (uskrsne i božićne drame te prizora iz života svetaca). Prag je imao stalno gradsko kazalište od 1738. godine u Kotcima, ali u 60-im godinama 18. stoljeća postaje poznato kao „narodno kazalište“. Na Maloj strani djelovalo je kazalište Thuna. Prvo kazalište koje je u programu imalo ponajprije češka djela bilo je Domoljubno kazalište (Vlastenské divadlo), koje je osnovao grof Franz Nostitz-Rieneck, a koje je počelo 
raditi na Konjskom trgu (Vaclavske namesti) 8. lipnja 1786. godine i koje je narod nazvao „Buda“.

Josef Kajetan Tyl oživio je amaterski kazališni pokret uvjeren u važnu ulogu narodno-društvenog kazališta, vodeći u godinama 1834. - 1837. vlastitu dobrovoljnu skupinu glumaca u tzv. Kajetanskom kazalištu ( $\mathrm{Ka}$ jetańské divadlo). Godine 1846. pozvan je za voditelja čeških predstava u Državnom kazalištu (Stavovské divadlo). U Tylovim postignućima najveće značenje imaju kazališne umjetnosti (Plavec, 1941).

\section{Završetak}

Romantizmu kao pokretaču demokratskih procesa snagu je davala široka formula kulture koja je gradila zajednicu mišljenja, povezanu komunikacijskom efektivnošću. Demokracija je nahrupila kroz široka vrata romantičarskog projekta kulture, iako je teren pripremilo prosvjetiteljstvo, izjednačavajući ideju slobode s vladavinom prava (Filipowicz, 2018, 8). Ono što se nije uspjelo postići putevima prava u doba prosvjetiteljstva, ostvario je romantizam stazama kulture. Korifeji romantičarskog bunta propagirali su protivljenje svim jednolikim uzorima, šablonama i hijerarhiji, čiji su nositelji bili kako katolička philosophia perennis, tako i univerzalistički prosvjetiteljski racionalizam (Sitek, 2006, 16). Romantizam je otkrio neograničenu raznovrsnost kultura, ali i mnoštvo i nesrazmjernost vrijednosti koje se pojavljuju u okviru svake od njih (načelo pluralizma). Mnoštvo i jednakost raznovrsnih kultura je oružje kojim je romantizam kreirao vlastito shvaćanje poretka, napretka i savršenstva, borio se protiv klasičnih ideala i podrivao vjeru u jedan monistički sustav vrijednosti, u jedan kriterij društvenih promjena (načelo slobode, suvereniteta i jednakosti). Romantizam je bio golem korak na putu prema ostvarivanju koncepcije pluralizma vrijednosti, širokoga građanskog sudjelovanja u nacionalnoj kulturi, vodio k otvorenom i tolerantnom društvu (načelo konsenzusa). Navedena načela, koja danas u društveno-političkoj stvarnosti čine demokratski kanon, romantizam je u znatnoj mjeri ostvario ili im prokrčio put u sferi kulture.

Naslovnu kategoriju, odnosno demokratizaciju kulture, treba shvatiti kao višeaspektnu pojavu postupnih i nepovratnih procesa inovacija koje su zahvatile sferu kulture, jezika, sustava formi iskaza te formiranja različitih 
društvenih i kulturnih institucija, koje su - stvarajući nove književne kanone, redefinirajući suvremene nacionalne identitete - na kraju pridonijele nastanku modernih država.

\section{Literatura}

Berlin, I. (2003). Korzenie romantyzmu. Poznań: Wydawnictwo ZYSK i S-KA

Bielik-Robson, A. (2008). Romantyzm, niedokończony projekt. Eseje. Kraków: Universitas.

Brtáň R. (1972). Pol'ska povstalecká pieseň v medzislovanských kontaktoch. U: Zwiazki i paralele literatur polskiej i stowackiej. Księga referatów wygloszonych na sesji naukowej polsko-słowackiej w dniach 11-13 maja 1970 roku. Wrocław: Ossolineum, str. 55-65.

Chlebowczyk, J. (1979). Świadomość historyczna jako element procesów narodotwórczych we wschodniej Europie Środkowej. U: Polska, czeska i stowacka świadomość historyczna XIX wieku. Materiaty sympozjum polsko-czechostowackiej komisji historycznej 15-16 XI 1977. Pod red. R. Hecka. Wrocław: Ossolineum, str. 9-24.

Filipowicz, S. (2018). Demokracja. Interpretacja wyznania wiary. Warszawa: Wydawnictwo Sejmowe.

Foucault, M. (2005). Stowa i rzeczy. Archeologia nauk humanistycznych. Przeł. T. Komendant i A. Tatarkiewicz. T. II. Gdańsk: Słowo/obraz terytoria.

Gołąbek, J. (1924). ,Jeszcze Polska nie zginęła“ wśród Stowian. „Przegląd Humanistyczny" r. 3, str. 137-172.

Goszczyńska, J. (2008). Synowie słowa. Myśl mesjanistyczna w słowackiej literaturze romantycznej. Warszawa: Wydawnictwo Uniwersytetu Warszawskiego.

Janaszek-Ivaničková, H. (1978). Kochanek Stawy: studium o L'udovicie Stúrze. Katowice: Wydawnictwo Śląsk.

Kalista, Z. (1942). Selské čili sousedské hry českého baroka. Praha: Melantrich.

Kočí, J. (1978). České národni obrození. Praha: Svoboda.

Krčmery, Š. (1927). Z rukopisov Sama Chalupku. „Sbornik Matice slovenskej“ V, zoš. $3-4$, str. 95-115.

Kuziak, M. (2009). Romantyzm a nowoczesność? U: Romantyzm i nowoczesność. Red. M. Kuziak. Kraków: Universitas, str. 5-13.

Lyotard, J. F. (1997). Kondycja ponowoczesna. Raport o stanie wiedzy. Przeł. M. Kowalska, J. Migasiński. Warszawa: Aletheia.

Macura, V. (1995). Znameni zrodu. Praha: H\&H.

Magnuszewski, J. (1956). Mickiewicz wśród Stowaków. Wrocław: Ossolineum.

Makowski, S. (1999). Mickiewiczowska kategoria poezji romantycznej. U: Adam Mickiewicz i kultura światowa. Materiały z międzynarodowej konferencji GrodnoNowogródek, 12-17 maja 1997 roku w 5. księgach. Księga 1. Pod red. S. Makowskiego i E. Szymanisa. Warszawa: Wydawnictwo Uniwersytetu Warszawskiego. 
Maleszyński, D. (2002). Człowiek $w$ tekście. Formy istnienia wedtug literatury staropolskiej. Poznań: Wydawnictwo Naukowe UAM.

Orłoś, T. (2000). Czeskie odrodzenie narodowe i językowe. Kraków: Wydawnictwo Oddziału Polskiej Akademii Nauk.

Plavec, J. (1941). František Škroup. Praha: Melantrich.

Sitek, R. (2006). Isaiaha Berlina ontologia społeczeństwa liberalnego. U: Demokracja. Między ideałem a praktyka, teoria a empirią. Poznań: Wyższa Szkoła Nauk Humanistycznych i Dziennikarstwa, str. 12-20.

Stefanowska, Z. (1962). Historia i profecja. Studium o „, Ksieggach narodu i pielgrzymstwa polskiego "Adama Mickiewicza. Warszawa: Wydawnictwo Literackie.

Szyjkowski, M. (1947). Polski romantyzm w czeskim życiu duchowym. Poznań: Instytut Zachodni.

Szyjkowski, M. (1948). Czeskie odrodzenie narodowe w XIX wieku. Łódź: Czytelnik.

Štefánek, A. (1937). Kollárov nacjonalizmus. U: Slovenská vzájemnost 1836-1936, Sborní k prací k 100. výročí vydán í rozpravy Jana Kollárn o slovansk é vzájemnosti. Red. J. Horák. Praha: Nákladatelství České akademie věd a uměni (Praha 1938), str. 339-389.

Zieliński, B. (2000). Hymnografia słowiańska XIX wieku a idea Europy Środkowej. U: Słowacja w obliczu Europy. Sonda. Materiały z konferencji naukowej pod red. Haliny Janaszek-Ivaničkovej. Katowice:Wydawnictwo Uniwersytetu Śląskiego, str. 34-49.

Zieliński, B. (2018). Hymnografia krajów byłej Jugosławii po roku 1989 roku. U: Z polskich Studiów Slawistycznych, seria 13, t. 1. Pod red. B. Zielińskiego. Prace na XVI Międzynarodowy Kongres Slawistów w Belgradzie. Poznań: Wydawnictwo Naukowe UAM, str. 313-322. 